КРАСИНА Евгения Александровна - старший преподаватель кафедры английского языка факультета мировой экономики Дипломатической академии МИД России (119021, Россия, г. Москва, ул. Остоженка, 53/2, cmp. 1; lizza-sun@mail.ru)

\title{
«СОСЕДЕЙ НЕ ВЫБИРАЮТ ВЗГЛЯД НА ВЗАИМООТНОШЕНИЯ РОССИИ И ЕВРОСОЮЗА
}

\begin{abstract}
Аннотация. В статье говорится о том, что прагматичная Европа никогда не горела желанием помочь России в трудные периоды. Декларируемое на словах перспективное сближение за почти 30 лет совместной истории по многим позициям привело даже к отдалению из-за не оправданного ничем, кроме экспансии в ущерб России, расширения НАТО на Восток. Автор подчеркивает, что с отдельными странами Евросоюза наперекор Вашингтону и его сателлитам из стран Центральной и Восточной Европы (Польша и Прибалтийские республики) развивается успешное сотрудничество для улучшения обеспечения их энергоресурсами. В статье делается вывод, что выстраивание Россией защиты от приближения НАТО, оборонительные действия при грузино-осетинском конфликте и при кризисе на Украине (защита русского народа от бандеровских банд), преподнесенные Западом как агрессия, послужили поводом для изоляции России, беспрецедентной информационной войны, введения санкций. Автор приходит к выводу, что таким образом Запад проверял твердость намерений России отстаивать имеющиеся собственные интересы и желание проводить самостоятельную политику, провозглашенные В. Путиным на Мюнхенской конференции по безопасности в 2007 г. В статье подчеркивается, что Россия старается со всеми странами выстраивать дружественные, равноправные, взаимовыгодные отношения. Ключевые слова: Европа, Россия и Евросоюз, Владимир Путин, мюнхенская речь, расширение НАТО, политика доминирования США, санкции, перспективы сотрудничества России и ЕС, Брексит, внешняя политика России, Польша и Прибалтийские республики, Германия, Франция, Вашингтон, энергоресурсы, США и Россия
\end{abstract}

С соседом дружись, но за саблю держись. (Русская народная пословица)

Все признают, что для того, чтобы иметь хороших соседей, мы также должны быть хорошими соседями.

Это относится ко всем сферам человеческой деятельности.

Гарри Трумэн

\section{Трудности во взаимоотношениях России с Евросоюзом}

Взаимоотношения России с ЕС подвергались большим колебаниям из-за разного понимания процессов, происходящих в России и с участием России. В начале 1990-х при президенте Б. Ельцине Россия тяготела больше к США. Они, как отмечает китайский профессор Цзинь Цаньжун, оказали большое влияние на внедрение либеральной экономической модели, сопровождавшейся быстрым переходом к рыночным отношениям, «шоковой терапией», приватизацией государственных предприятий ${ }^{1}$. Пойдя по этому пути, Россия скатилась в экономический хаос, из которого не может выкарабкаться до сих пор. С Евросоюзом, отказавшим правительству Е. Гайдара в выделении стабилизационного кредита в 5-6 млрд долл., складывались отношения, опиравшиеся на предположение о постепенном сближении и более тесном взаимодействии с РФ при последовательной европеизации самой России. Б. Ельцин высказывал

\footnotetext{
${ }^{1}$ GT: высокомерие по отношению к России играет с Вашингтоном злую шутку. 27.02.2018. Доступ: https://russian.rt.com/inotv/2018-02-27/GT-visokomerie-po-otnosheniyu-k (проверено 27.04.2020).
} 
пожелание даже о вступлении в ЕС, но «Соглашение о партнерстве и сотрудничестве» (СПС, 1997 г.) не привело к росту торговых связей и улучшению взаимодействия. На это повлияла поддержка Брюсселем сепаратизма в Чечне, а также слабое здоровье российского президента.

В начале нулевых годов, после ухода Б. Ельцина, между Россией и Евросоюзом возросло сотрудничество в сфере экономики при том, что не происходило сближение политических и экономических систем, и даже увеличилось напряжение в политических отношениях между ними. С другой стороны, со странами - членами Евросоюза в большинстве своем у России складывались более успешные взаимоотношения на базе практического сотрудничества во всех сферах жизни, т.к. они основывались на взаимном прагматичном интересе. Эта специфика взаимоотношений со странами Евросоюза в рамках двустороннего сотрудничества возникла давно и действовала даже в период «холодной войны». Даже с некоторыми странами Центральной и Восточной Европы, с которыми у России традиционно складывались трудные отношения, торговля росла, как с ЕС в целом. Москве оказалось комфортнее иметь дело со столицами стран Евросоюза, чем с брюссельской бюрократией, ставившей интеграцию России в европейское экономическое пространство в зависимость от развития процессов демократизации при безусловном лидерстве ЕС в установлении правил игры.

Трудности в отношениях с Евросоюзом возникают к тому же из-за того, что почти все страны входят в военный Североатлантический блок - НАТО, который после распада СССР и роспуска Организации стран Варшавского договора очень быстро нашел объект противостояния в лице России. Поддержанное Вашингтоном нападение Грузии на Южную Осетию, приведшее к гибели российских миротворцев 8 августа 2008 г., средства массовой информации стран НАТО представили актом агрессии России. И только спустя целый год оголтелой антироссийской пропаганды специальная комиссия Евросоюза, возглавляемая Хайди Тальявини, возложила вину за разжигание вооруженного конфликта на отдавшего преступный приказ президента Грузии Михаила Саакашвили ${ }^{1}$.

Государственный переворот на Украине, обернувшийся, по сути, гражданской войной, был поддержан США, Польшей, Германией и Францией. Об этом неоднократно говорил В. Путин, отмечая, что «Евросоюз и США не пожелали разобраться в подоплеке политического кризиса на Украине и поддержали силовой захват власти в стране» ${ }^{2}$. Е. Марков в своей работе «Истоки конфронтации со странами Запада и мюнхенская речь Владимира Путина» отмечает также то, что министр иностранных дел России Сергей Лавров называет свержение законной власти на Украине «позором Европы» [Марков 2019: 107]. Восстановление нормальных отношений с Россией и снятие санкций в настоящее время Евросоюз связывает с решением внутриукраинского конфликта и с выполнением минских соглашений, исполнять которые Киев, очевидно, не желает. Россия не является стороной конфликта, хотя и оказывает гуманитарную поддержку Донецкой и Луганской народным республикам.

На наш взгляд, взаимоотношения с ЕС у России значительно осложнились в 2004 г. после приема в него Польши, Латвии, Литвы и Эстонии, которые слепо подчинились Вашингтону и, зачастую в ущерб себе, стали занимать ярую антироссийскую позицию по всем вопросам сотрудничества. Профессор А. Валицкий, отвечая на вопрос: «Могут ли польско-российские отношения быть хорошими?» - в 2005 г. на страницах журнала «Аркана» не поддержал про-

\footnotetext{
${ }^{1}$ Косарев Д. Европравда. - Российская газета. 01.10.2009. Доступ: https://rg.ru/2009/10/01/gruzia. html (проверено 27.03.2020).

2 Путин: ЕС и США поддержали государственный переворот на Украине. 15.06.2017. Доступ: https://tass.ru/politika/4337309 (проверено 27.03.2020).
} 
водимую польскими политиками «концепцию осажденной крепости», оправдывающую полное подчинение США. Он писал: «В особенности важным было бы конструктивное подключение Польши к процессу расширения сферы российско-немецкого экономического сотрудничества. Это позволило бы направить внимание немцев на экономическую экспансию, к которой мы могли бы присоединиться, а также укрепить пропольские настроения в России и Германии, устраняя угрозу нового Рапалльского договора ${ }^{1}$ и способствуя постепенному отказу немцев от выдвижения материальных претензий к Польше» [Пискорский 2019]. По прошествии почти 15 лет можно с уверенностью сказать, что к нему не прислушались, и польские политики при каждом удобном случае всеми силами стараются уязвить Россию, причем информационные вбросы осуществляются на государственные средства. Об этом поведал белорусский публицист, эксперт в области политики Алексей Дзермант. Он также заявил, что внешние силы в лице Украины, Польши и Прибалтики пытаются настроить граждан их республики против российских соседей, чтобы не допустить углубления сотрудничества и единения России и Белоруссии ${ }^{2}$. Анджей Валицкий, говоря об истоках современной антироссийской политики, которая соответствует целям политики и стратегии США в Восточной и Центральной Европе, упоминал труды 3. Бжезинского, который еще в 1990-х гг. открыто заявлял, что государства этого региона должны играть роль вассалов и инструментов Вашингтона, а не выступать самостоятельными субъектами. Прослеживается аналогия с Восточным валом, выстраиваемым Гитлером по линии ПантераВотан от Азовского до Балтийского морей в 1943 г. на Восточном фронте «для зашиты Европы от большевизма» [Пискорский 2019]. Исходя из этого, можно заключить, что не будь войны 08.08.2008 г., не будь Крыма, Донбасса, Сирии, антироссийские силы в вышеозначенных странах все равно бы вели русофобскую пропаганду, выполняя задачу быть барьером для желающих плодотворно и взаимовыгодно сотрудничать с Россией.

\section{Перспективы налаживания добрососедских отношений России с Евросоюзом}

После введения санкций Евросоюзом и ответных контрсанкций связующим звеном осталось снабжение Европы энергоресурсами и сырьем. Как в годы «холодной войны» Германия пошла, наперекор США, на небывалую сделку «газ в обмен на трубы», так и сейчас грандиозное противодействие Вашингтона и его сателлитов наталкивается на большое желание Германии и других стран старой Европы обеспечить себя бесперебойной поставкой дешевого трубопроводного газа по строящемуся «Северному потоку-2». Все другие интеграционные процессы, о которых было заявлено по инициативе ЕС на Санкт-Петербургском саммите (2003 г.): о создании четырех общих пространств - экономического; свободы, безопасности и правопорядка; сотрудничества в области внешней безопасности; науки и образования, включая культуру, остались в виде деклараций. Конкретные запросы России встречали в ЕС жесткий подход. Так, Россия с трудом добилась согласия ЕС на вступление в ВТО, а также приемлемых усло-

1 Рапалльский договор 1922 г. - соглашение, установившее дипотношения между РСФСР и Германией, содержавшее порядок урегулирования разногласий, взаимный отказ от возмещения убытков во время Первой мировой войны. Германия отказывалась от претензий, вытекавших из нарушения в Советской России как прав немецких граждан, так и прав Германии, при условии, что РСФСР не будет удовлетворять аналогичные претензии других государств. Договор вызвал сильнейшее беспокойство среди западных стран.

2 «Мы окружены с трех сторон»: белорусский эксперт заявил, что Украина, Евросоюз и Прибалтика пытаются отдалить Минск от Москвы. 10.02.2019. Доступ: https://vashinovosty.mediasalt.ru/my_ okruzheny_s_trh_storon_belorusskiy_ekspert_zayavil_chto_ukraina_evrosoyuz_i_pribaltika_pytayutsya_ otdalit_minsk_ot_moskvy (проверено 27.03.2020). 
вий сухопутной транспортной связи с Калининградом. На это уходили годы. Брюссель занял жесткую экспансионистскую позицию, продвигая в зону жизненных интересов России проект «Восточное партнерство» и активно поддерживая «цветные революции» на постсоветском пространстве.

Европа очень негативно восприняла строительство В. Путиным вертикали власти, увязывая его со свертыванием демократии, а также установлением контроля государства над экономикой. В докладе «Имея дело с Россией: следующая фаза» в 2006 г. эксперты отметили, что если этот период будет «не преходящей фазой в переходе к рыночной экономике и демократии, а долговременной тенденцией, то приведет к государственно-корпоративной бюрократической стагнации под контролем небольшой корыстной и самоувековечивающейся группы» [Lyne, Talbott, Watanabe 2006: 73-74]. Тут есть над чем задуматься, особенно по прошествии 13 лет со времени этого доклада, которые были насыщены событиями, требующими принятия судьбоносных для России решений. Вряд ли без усиления государства во всех сферах жизни эти решения были бы такими, какие были приняты руководством в 2008 и 2014 гг. Хотя как раз они ожидаемо привели к ухудшению взаимоотношений с Евросоюзом в наибольшей степени, т.к. Брюссель вместо триумфального шествия Восточного партнерства и по Украине, получил головную боль, в т.ч. из-за своих непродуманных и несогласованных с Россией действий, игнорирующих ее интересы. Накопившийся в отношениях с Евросоюзом клубок противоречий решить в ближайшее время будет однозначно трудно, да и невозможно из-за позиции Брюсселя.

Не подлежит сомнению то, что Россия остается потенциальным стратегическим партнером Европы. Она играет существенную роль в обеспечении глобальной и европейской безопасности, остается четвертым по значимости экономическим партнером Европы после США, Китая и Швейцарии и, как уже отмечалось, надежным поставщиком энергоресурсов. Также у обеих сторон существует тревога за свое положение в мире в текущем столетии, что должно способствовать налаживанию отношений. К тому же для России Евросоюз является самым крупным торгово-экономическим партнером: в евро номинирована значительная часть наших золотовалютных резервов, хоть и медленно, но растет экономико-технологическое сотрудничество. Россия заинтересована в процветании Европейского союза, т.к. они имеют общую и богатую на события историю, близкие культуры, религию и географическое положение.

Претензии к России часто возникают из-за «блокового мышления», в основе которого находится приоритет силы военно-политического блока НАТО. «Попытки внедрять в общественное сознание негативную повестку, проводить политику, основанную на рецидивах блокового мышления, не могут не вызывать обеспокоенность, - сказал глава МИДа России С. Лавров, выступая на заседании форума общественности «Петербургский диалог» в Бонне 18 июля 2019 г. - Руководствуясь концепцией сдерживания, НАТО продвигает свою военную инфраструктуру к границам России, продолжает форсированное принятие в свой состав новых членов. А ведь достаточно взглянуть на данные о размерах военных бюджетов России и стран Альянса - у НАТО в двадцать раз больше - чтобы понять, кто кому угрожает» 1 .

Все хорошо понимают, что в нарушение своих обещаний США стали принимать в НАТО не только восточноевропейские страны, но и бывшие советские республики, а озвученным намерением приема Грузии и Украины вообще поставили Россию в очень уязвимую позицию в сфере обеспечения своей бе-

\footnotetext{
1 Выступление министра иностранных дел России С.В. Лаврова на открытии форума общественности «Петербургский диалог». Бонн, 18 июля 2019 г. 18.07.2019. Доступ: https://www.rus.rusemb.org.uk/ article/319 (проверено 27.03.2020).
} 
зопасности. Россия вынуждена была оказывать сопротивление высокомерной агрессивной политике стран англосаксонского мира. Напротив, в случае оказания реальной помощи России после распада СССР, включения ее на равных в систему международной безопасности, имея с ней настоящее партнерство и сотрудничество, Вашингтон и Евросоюз имели бы в лице России верного союзника, да и мир мог бы быть другим. Но ведя себя как победитель, демонстрируя свое всемогущество, диктуя условия «проигравшей стороне», Запад упустил шанс сделать мир лучше.

Евросоюз в своем становлении в настоящее время проходит тоже очень трудный период. Даже в Германии - основной движущей силе Евросоюза, получающей основные дивиденды, но и несущей большие расходы из-за санкционной экономической политики Вашингтона, появились признаки рецессии, а Брексит вынудит повысить расходы еще больше. Внутренние неурядицы Евросоюза, к которым в настоящее время добавилась эпидемия коронавируса, должны бы мотивировать Европу на улучшение отношений с Россией, чтобы снизить финансовые потери от взаимных санкций. Но этого не происходит. Так что состояние вялотекущего сотрудничества у Евросоюза с Россией продлится достаточно долго. Выйти из-под власти Вашингтона, когда 22 страны из 28, составляющих ЕС, являются членами НАТО, не позволят союзнические отношения в блоке. Зафиксировать смерть блока вслед за констатацией Э. Макроном «смерти мозга НАТО» они просто не решатся. Ангела Меркель заявила о большей необходимости НАТО, чем даже в период «холодной войны», и практически одновременно на съезде партии «Христианский демократический союз» (ХДС) высказалась за налаживание с Россией добрососедских отношений. Логику ее высказываний можно понять, если предположить, что в последнем случае она выступила только как канцлер Германии.

Можно предположить, что стимулирующим фактором по отношению к сотрудничеству Европы с Россией будет диверсификация Россией поставок углеводородов еще и в страны Азиатско-Тихоокеанского региона. Вступление в строй трубопроводной системы «Восточная Сибирь - Тихий океан» (ТС ВСТО) и газопровода «Сила Сибири» уменьшают зависимость страны от западных партнеров. Нарастающее взаимодействие России с Китаем еще и в военной сфере, по словам почетного профессора стратегических исследований Пола Дибба из Центра стратегических и оборонных исследований при Австралийском национальном университете, может бросить вызов американской мощи. «На фоне постепенного экономического спада в России и быстрого роста в Китае можно было бы ожидать, что Москва поддержит усилия Запада, направленные на то, чтобы сбалансировать деятельность Китая, и не станет подрывать их. Однако появились многочисленные свидетельства того, что Россия и Китай продолжают укреплять свои отношения, что явным образом может иметь негативные геополитические последствия для Запада» [Белов 2019].

На основании вышеизложенного можно сделать следующие выводы.

1. Первопричиной ухудшения отношений между Россией и Европой стало поспешное расширение НАТО на Восток при президенте Б. Клинтоне, случившееся вопреки заверениям Дж. Буша и госсекретаря Джеймса Бейкера, данным СССР при объединении Германии. Экспансия Евросоюза с Восточным партнерством не только без учета интересов России, но с большим желанием ущемить эти интересы, дополнила проблемы в сотрудничестве и выключила партнерство на неопределенный срок.

2. Отношения с Евросоюзом и даже с Польшей и Прибалтийскими республиками вполне могут стать добрососедскими на основе взаимовыгодного сотрудничества. Конфронтация и русофобия - их личный выбор. «Мы никогда 
не инициировали какое-либо ухудшение, осложнение, даже минимальный откат в отношениях между нашей страной и ЕС», - сказал глава МИДа России С. Лавров ${ }^{1}$.

3. России не стоит ожидать снятия всех санкций. Санкции будут, т.к. США всеми силами будут препятствовать возрождению России как великой мировой державы, и пока она будет проводить самостоятельную политику. Европейский бизнес надеется на снятие санкций Евросоюзом для улучшения условий сотрудничества. Гендиректор Ассоциации европейского бизнеса в РФ Франк Шауфф на Восточном экономическом форуме в сентябре 2019 г. заявил: «Я не знаю ни одну компанию ЕС, которая бы ушла из РФ из-за санкций» 2 . Вероятно, европейские компании опасаются потерять российский рынок из-за конкуренции.

4. Евросоюз, став неожиданным соседом России на севере, вполне может стать соседом вдоль всех западных границ. Превратившись в исторически короткий период в супергосударство с имперскими наклонностями, Евросоюз может выйти из-под жесткой опеки англосаксов после ухода Великобритании (Брексит) и охлаждения отношений с США из-за их протекционистской политики. Но эта империя нового типа будет стремиться к доминированию в отношениях с Россией, вовлечению ее в сферу своего влияния. Только близкие к союзническим отношения с Китаем могут умерить экспансионистский пыл Европы. Эта формула может работать и в обратном направлении. Сбалансированные отношения с Китаем и Евросоюзом позволят России с уверенностью смотреть в будущее.

\section{Список литературы}

Белов А. 2019. Strategist: предсказания Бжезинского начинают сбываться. 29.11.2019. Доступ: https://regnum.ru/news/polit/2793434.html (проверено 27.04.2020).

Марков Е.А. 2019. Истоки конфронтации со странами Запада и мюнхенская речь Владимира Путина. - Вестник Балтийского федерального университета им. И. Канта. Сер. Гуманитарные и общественные науки. № 1. С. 104-113.

Пискорский M. Myśl Polska (Польша): польский интеллектуал пишет правду о России(часть 1).26.10.2019.Доступ:https://inosmi.ru/politic/20191026/246090082. html (проверено 27.04.2020).

Lyne R., Talbott S., Watanabe K. 2006. Engaging with Russia. The Next Phase: A Report to the Trilateral Commission. Washington; Paris; Tokyo. The Trilateral Commission. ix + 182 p. URL: http://svop.ru/files/meetings/m005013388828463.pdf (accessed 27.04.2020).

1 Лавров сообщил, что Россия не станет сотрудничать с ЕС в ущерб взаимодействию с Китаем. 11.11.2019. Доступ: https://tass.ru/politika/7100733 (проверено 27.03.2020).

2 Байназаров Э. «Я не знаю ни одну компанию ЕС, которая бы ушла из РФ из-за санкций». 09.09.2019. Доступ: https://iz.ru/918350/elnar-bainazarov/ia-ne-znaiu-ni-odnu-kompaniiu-es-kotoraiaushla-iz-rf-iz-za-sanktcii (проверено 27.03.2020). 
KRASINA Evgeniya Aleksandrovna, Senior Lecturer at the Chair of English Language, Faculty of World Economy, Diplomatic Academy of the Ministry of Foreign Affairs of Russia (53/2 Ostozhenka St, Moscow, Russia, 119021; lizzasun@mail.ru)

\title{
«THEY DON'T CHOOSE NEIGHBORS»: A LOOK AT THE RELATIONS BETWEEN RUSSIA AND THE EUROPEAN UNION
}

\begin{abstract}
The article says that pragmatic Europe has never been eager to help Russia in difficult periods. The promising rapprochement declared in words over nearly 30 years of shared history in many positions has even led to a cooling in relations due to the expansion of NATO to the East, justified by nothing but enlargement to the detriment of Russia. The author also emphasizes that Russia is developing successful cooperation with individual EU countries to improve their energy supply in defiance of Washington and its satellites from Central and Eastern Europe (Poland and the Baltic republics). The article concludes that Russia's building up defense against NATO's approach, defensive actions during the GeorgianOssetian conflict and Ukraine's crisis (protecting the Russian people from Bandera gangs), presented by the West as aggression, served as an excuse for the isolation of Russia, an unprecedented information war, and the introduction of sanctions. The author concludes that in this way the West checked the firmness of Russia's intentions to defend its own interests and the desire to pursue an independent policy proclaimed by V. Putin at the Munich Security Conference in 2007. The article emphasizes that Russia is trying to build friendly, equal, mutually beneficial relations with all countries.

Keywords: Europe, European Union and Russia, Vladimir Putin, Munich speech, NATO expansion, US dominance policy, sanctions, Russian-EU cooperation prospects, Brexit, Russian foreign policy, Poland and the Baltic republics, Germany, France, Washington, energy supply, USA and Russia
\end{abstract}

\section{УДК 325}

ШОГУНЦ Анна Вардановна - аспирант Института Европы РАН (125009, Россия, г. Москва, ул. Моховая, 11, cmp. 3; annashoghunts@mail.ru)

\section{СОВРЕМЕННОЕ ИЗМЕРЕНИЕ МИГРАЦИОННОЙ ПОЛИТИКИ ИТАЛИИ}

\begin{abstract}
Аннотация. Целью данной статьи является рассмотрение политики в области миграции, проводимой правыми партиями в Италии в 2018-2019 гг. Метод исследования заключается в анализе решений, законов, мер, принятых первым правительством Дж. Конте в попытке ограничить массовый приток мигрантов. В статье автор исследует влияние итальянской миграционной политики на сокращение миграции из неблагополучных стран Африки, а также ее роль в увеличении популярности «Лиги» и ее лидера М. Сальвини. Результаты исследования вносят вклад в изучение итальянской миграционной политики на данном этапе и влияния на нее миграционного кризиса в Европейском союзе.
\end{abstract}

Ключевые слова: Италия, миграция, выборы, «Лига», Сальвини, Движение пяти звезд

И сследование политики правых партий в области регулирования миграции в Италии в 2018-2019 гг. представляется актуальным в силу того, что, начиная с середины 2010-х гг., Италия переживает период экономической нестабильности и больших социальных потрясений, вызванных миграционным кризисом в Европейском союзе, кульминацией которого стало прибытие в Европу миллионов мигрантов, ищущих убежище от войн и преследований в своих родных странах (как правило, из региона Северной и Центральной Африки и Ближнего Востока). Целью исследования является выявление ключевых событий проводимой правыми партиями миграционной политики, а также влияния этих 